\title{
IDENTIFIKASI REMBESAN LIMBAH CAIR DENGAN MENGGUNAKAN METODE GEOLISTRIK RESISTIVITAS KONFIGURASI WENNER- SCHLUMBERGER STUDI KASUS TPA SUMOMPO, MANADO
}

\author{
Friska Datunsolang ${ }^{1}$, Gerald Tamuntuan ${ }^{1)}$, As'ari $^{1}{ }^{1)}$ \\ ${ }^{1)}$ Jurusan Fisika Fakultas MIPA Universitas Sam Ratulangi, Manado \\ Email: priskadatunsolang@gmail.com; gtamuntuan@gmail.com; as.ari2222@yahoo.co.id
}

\begin{abstract}
ABSTRAK
Limbah cair atau lindi yang merupakan hasil degradasi sampah terutama pada lokasi tempat pengelolaan akhir (TPA) dapat meresap ke dalam tanah hingga mencemari sumber air tanah. Karena prosesnya yang terjadi dibawah permukaan maka penyebaran limbah cair relatif sulit untuk dideteksi. Pada penelitian ini telah dilakukan pengukuran geolistrik resistivitas untuk mengidentifikasi adanya rembesan serta penyebaran limbah cair disekitar TPA. Penelitian dilaksanakan disekitar TPA Sumompo, Manado dengan menggunakan konfigurasi WennerSchlumberger pada lima lintasan yang masing-masing berjarak $50 \mathrm{~m}$. Data pengukuran selanjutnya diinversi dengan menggunakan software Res2dinv hingga memunculkan profil resistivitas $2 \mathrm{D}$. Hasil analisis menunjukan adanya zona-zona resistivitas rendah yang diperkirakan sebagai daerah porous tersaturasi fluida. Pada lintasan 1, zona tersebut diinterpretasikan sebagai daerah rembesan dan akumulasi lindi, sementara pada lintasan-lintasan yang lain diperkirakan sebagai zona air tanah yang berpotensi tercemar lindi.
\end{abstract}

Kata kunci: Geolistrik,Lindi, TPA Sumompo

\section{IDENTIFICATION LIQUID OF WASTE BY USING GEOELECTRIC RESISTIVITY WENNER-SCHLUMBERGER CONFIGURATION THE LANDFILL STUDIES IN SUMOMPO,MANADO}

\begin{abstract}
Liquid waste or leachate which is the result of degradation of litter, especially in location where the final manegement of (TPA) can seep into the soil to contaminate groundwater sources. Because the process is going on under the surface of the liquid waste then spread relatively difficult to detect. This research has been conducted geoelectric resistivity measurement to identify the presence of wastewater seepage and spread around the landfill. Research conducted around the landfill Sumompo, Manado using Wenner-Schlumberger configuration on five tracks, each of which is 50 meters away. The next measurement data using software RES2DINV inverted to bring up the 2D profile. The result of the analysis showed the presence of low resistivity zones were estimated as the fluid saturated porous region. On track 1, the zone is interpreted as the accumulation of leachate seepage and region, while at the other trajectories estimated as zona of potentially contaminated groundwater leachete.
\end{abstract}

Keywords: Geoelectric, Leachate, TPA Sumompo

PENDAHULUAN

Aktivitas manusia dalam memanfaatkan alam selalu meninggalkan sisa yang dianggap sudah tidak berguna lagi sehingga diperlakukan sebagai barang buangan, yaitu sampah dan limbah (Widyatmoko dan Sintorini, 2002). Sampah adalah buangan padat merupakan polutan umum yang dapat menyebabkan turunnya nilai estetika lingkungan, membawa berbagai jenis penyakit, menimbulkan polusi, 
menyumbat saluran air, dan berbagai akibat negative lainnya. Di kota-kota besar untuk menjaga kebersihan sering kali menyingkirkan sampah ke tempat yang jauh dari pemukiman atau yang biasa disebut Tempat Pembuangan Akhir ( TPA). Sampah yang dibuang pada lokasi TPA akan mengalami pembusukan terutama pada sampah basah yang umumnya terdiri dari sampah organik, apalagi di Negara Indonesia merupakan Negara tropis yang mempunyai iklim panas dan kelembaban tinggi, hal ini merupakan faktor mempercepat terjadinya reaksi kimia, sehingga sampah lebih cepat membusuk (Widyatmoko dan Sintorini, 2000). Limbah dari timbunan sampah dapat menimbulkan cairan yang membahayakan yang disebut lindi.

Metode Geolistrik resistivitas merupakan salah satu metode geofisika yang memanfaatkan variasi resistivitas yang dapat digunakan untuk mendeteksi kontaminan cair dalam tanah yang sering diasosiasikan sebagai fluida konduktif (Suhendra, 2006; Oladapo dkk, 2013). Metode Geolistrik Resistivitas dilakukan dengan cara menginjeksikan arus ke permukaan bumi kemudian diukur beda potensialnya (Telford dkk, 1990).

Beberapa penelitian menunjukan bahwa metode Geolistrik dapat memetakan pencemaran air tanah. Grandis dan Yudistira (2002) melakukan penelitian dibekas TPA pasir Impun Bandung dan berhasil memperkirakan penyebaran kontaminan cair akumulasi rembesan limbah di daerah tersebut. Penelitian untuk identifikasi perembesan serta distribusi limbah cair dibawah permukaan juga telah dilakukan baik dalam skala laboratorium maupun lapangan oleh Ngadimin dan Handayani (2001), Suhendra (2006), serta Wahyono dan Sari (2007). Dalam penelitian ini telah dilakukan investigasi geolistrik resistivitas untuk mengidentifikasi rembesan dan penyebaran limbah cair di sekitar TPA Sumompo, Manado.

\section{Metode Penelitian}

Penelitian dilaksanakan di daerah sekitar tempat pembuangan akhir (TPA) Sumompo, Manado. Penelitian ini dilaksanakan pada bulan April 2015. Peta lokasi penelitian dan desain awal bentangan survei pemetaan geolistrik dapat dilihat pada
Gambar 1. Bentangan didesain untuk lima lintasan pengukuran dengan masing-masing lintasan mempunyai spasi $3 \mathrm{~m}$, jarak setiap lintasan $50 \mathrm{~m}$, dan panjang lintasan $72 \mathrm{~m}$. Pengambilan data geolistrik dengan menggunakan alat Resistivity \& IP meter MAE 612EM dengan mengikuti konfigurasi Wenner-Schlumberger (Gambar 2).

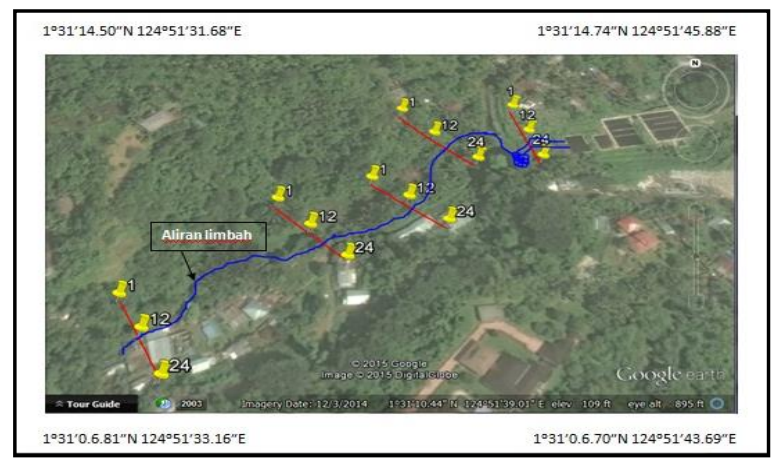

Gambar 1. Lokasi TPA Sumompo dan desain awal bentang pengukuran geolistrik (garis merah adalah bentang pengukuran geolistrik).

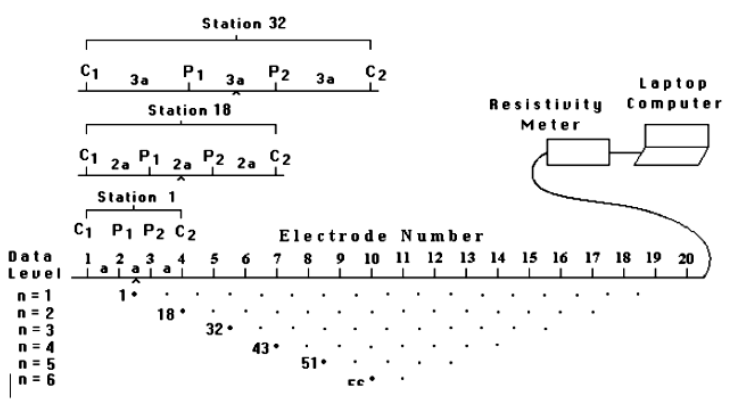

Gambar 2. Teknik pengukuran untuk mendapatkan profil 2D (Sumber: Loke dan Barker, 1996)

Pengolahan data geolistrik dilakukan dengan proses inversi menggunakan perangkat lunak RES2DINV. Adapun data yang digunakan sebagai input dalam proses inversi ini adalah distribusi nilai $\rho_{a}$, jarak antar elektroda, jumlah data, serta elevasi setiap elektroda.

\section{HASIL DAN PEMBAHASAN}

Nilai resistivitas yang diperoleh pada setiap lintasan relatif bervariasi dengan informasi kedalaman berkisar 10 meter dari permukaan. Penskalaan kontur citra resistivitas diatur pada interval $1-250 \Omega \mathrm{m}$ sehubungan dengan informasi yang dicari relatif berfokus pada nilai resistivitas rendah. Lindi merupakan cairan konduktif sehingga 
memiliki nilai resistivitas kecil, yaitu dibawah $10 \Omega$ m.

Gambar 3 hingga Gambar 7 menunjukkan citra resistivitas pada lima lintasan pengukuran (lintasan 1 hingga lintasan 5). Setiap gambar terdiri atas tiga bagian yang masing-masing menunjukkan citra resistivitas tanpa koreksi topografi (gambar bagian atas), elevasi setiap elektroda (gambar bagian tengah), dan citra resistivitas dengan koreksi topografi (gambar bagian bawah).

Pada lintasan 1, daerah bernilai resistivitas rendah, $<10 \Omega \mathrm{m}$, yang dicitrakan dengan warna biru muda hingga biru tua terlokalisasi pada dua bagian terpisah yang dibatasi oleh zona dengan nilai resistivitas tinggi (warna merah hingga ungu). Pada bagian kiri, zona resistivitas rendah berada pada jarak 15 - $27 \mathrm{~m}$ dengan kedalaman antara $2-10 \mathrm{~m}$. Sementara pada bagian kanan, terutama pada jarak 53-64 m dengan kedalaman antara 1,5 hingga $7 \mathrm{~m}$.

Lintasan 2 berada pada jarak $50 \mathrm{~m}$ dari lintasan 1. Lintasan ini berada pada elevasi $70 \mathrm{~m}$ dari permukaan laut. Informasi yang diperoleh sekitar $10 \mathrm{~m}$ dari permukaan. Berdasarkan gambar bagian yang terkoreksi topografi, zona dengan nilai resistivitas rendah $(<10 \Omega \mathrm{m})$ berada pada jarak $30-65$ $\mathrm{m}$ dari arah kiri dan kedalamannya bervariasi antara 3-10 m. Berbeda dengan lintasan 1, pada lintasan 2 hampir tidak ditemukan zona keras (daerah dengan nilai resistivitas tinggi) yang cukup signifikan.

Pada lintasan 3, zona resistivitas rendah berada pada kedalaman $3-10 \mathrm{~m}$ dengan posisi pada jarak $18-50 \mathrm{~m}$ dari titik nol pengukuran. Daerah dengan resistivitas paling rendah terdapat pada tiga titik utama yaitu sekitar $18 \mathrm{~m}, 35 \mathrm{~m}$, dan $45 \mathrm{~m}$ dari titik nol pengukuran. Pola dari zona resistivitas rendah pada lintasan ini relatif bersesuaian dengan pada lintasan 2 .

Lintasan 4 berada pada ketinggian sekitar $75 \mathrm{~m}$ dari permukaan laut. Sebaran resistivitas didominasi oleh nilai resistivitas dibawah $100 \Omega \mathrm{m}$. Zona resistivitas dibawah $10 \Omega \mathrm{m}$ terlihat terpolarisasi pada jaak $18-33$ $\mathrm{m}$, dan $45-68 \mathrm{~m}$. Pada lintasan ini titik zona keras sangat kecil dibandingkan dengan lintasan yang lain. Sementara, lintasan 5 berjarak $50 \mathrm{~m}$ dari lintasan 4 . Lintasan ini berada pada ketinggian sekitar $60 \mathrm{~m}$ dari permukaan laut dan membentuk kemiringan tetap kearah kanan. Informasi kedalaman yang diperoleh adalah sekitar $10 \mathrm{~m}$. Zona dengan resistivitas rendah terlokalisasi pada jarak sekitar $33-60 \mathrm{~m}$.

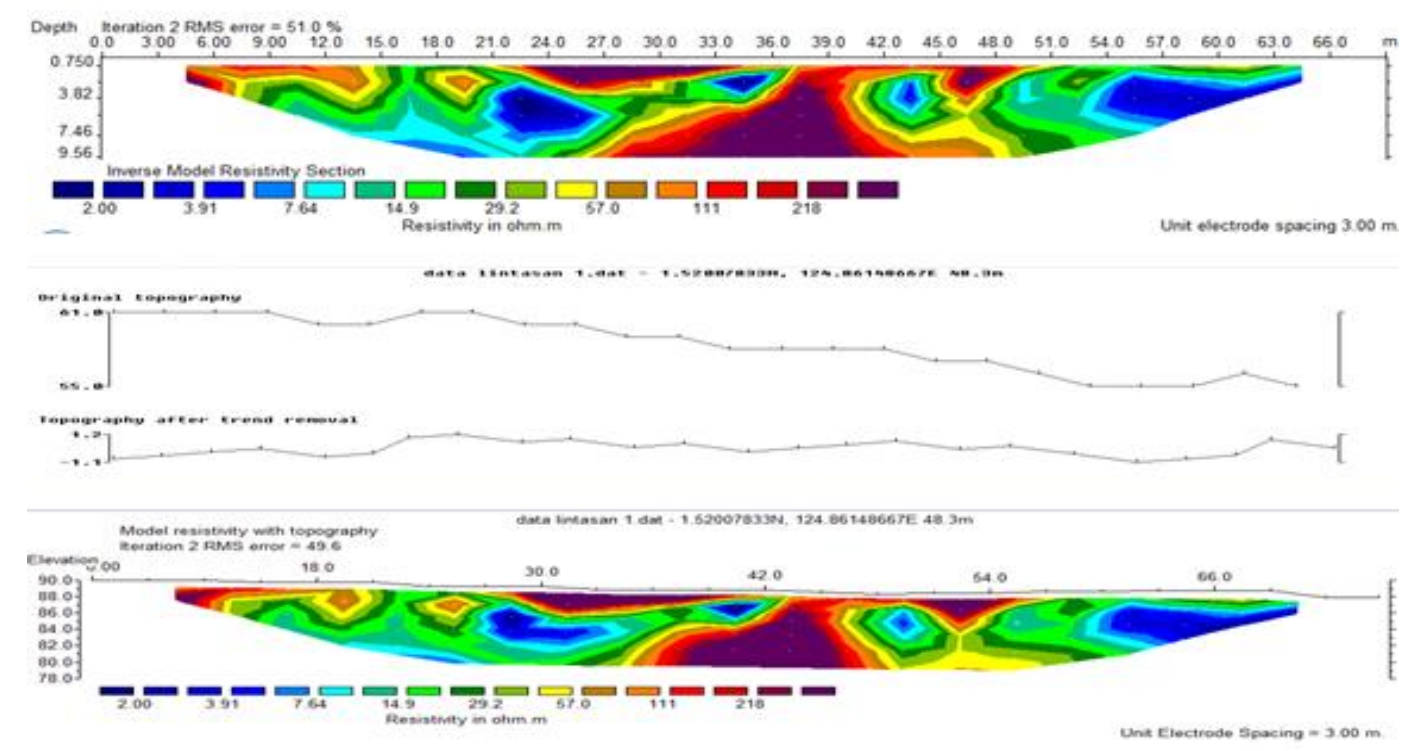

Gambar 3. Citra resistivitas pada lintasan 1 


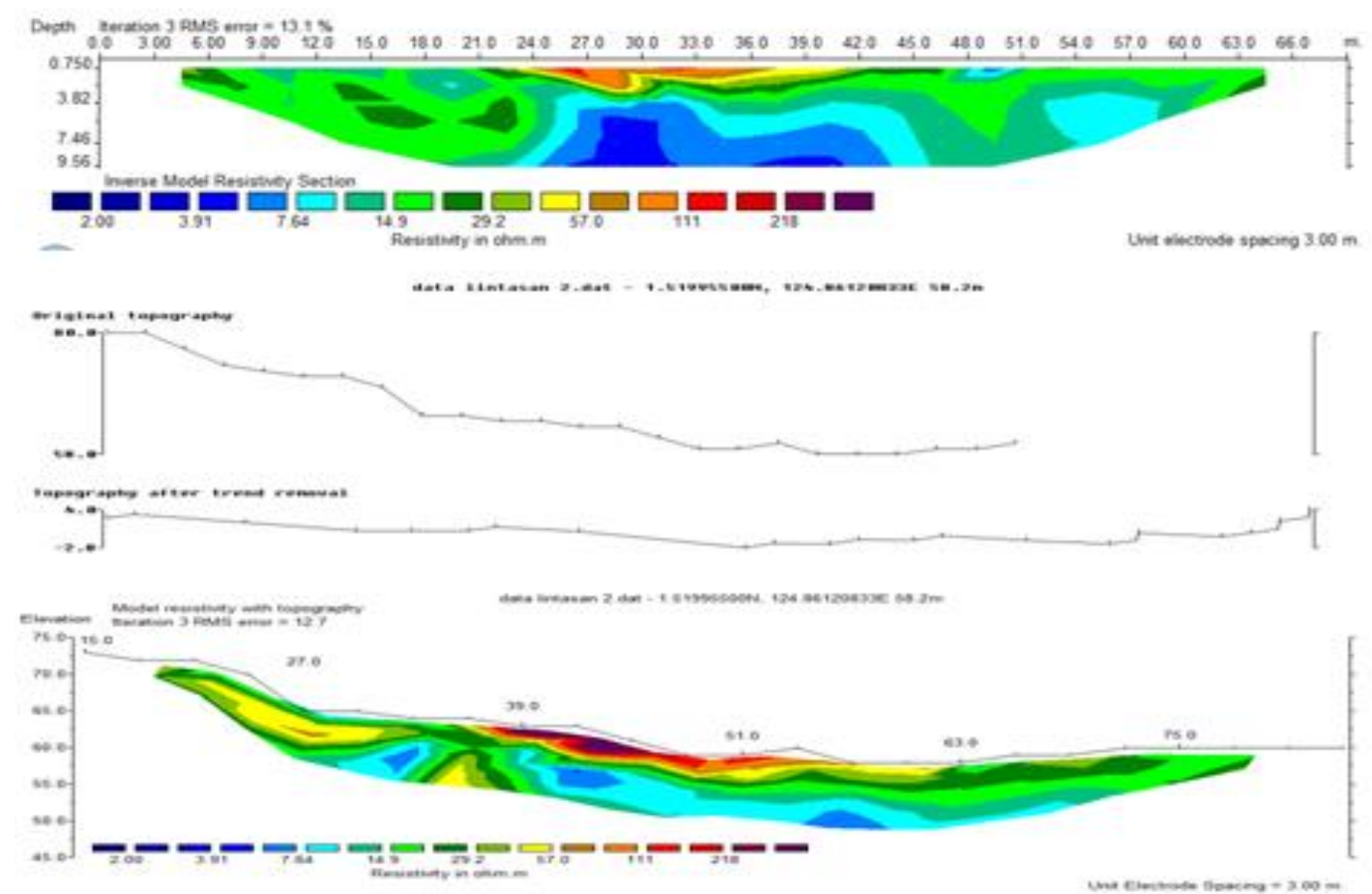

Gambar 4. Citra resistivitas pada lintasan 2

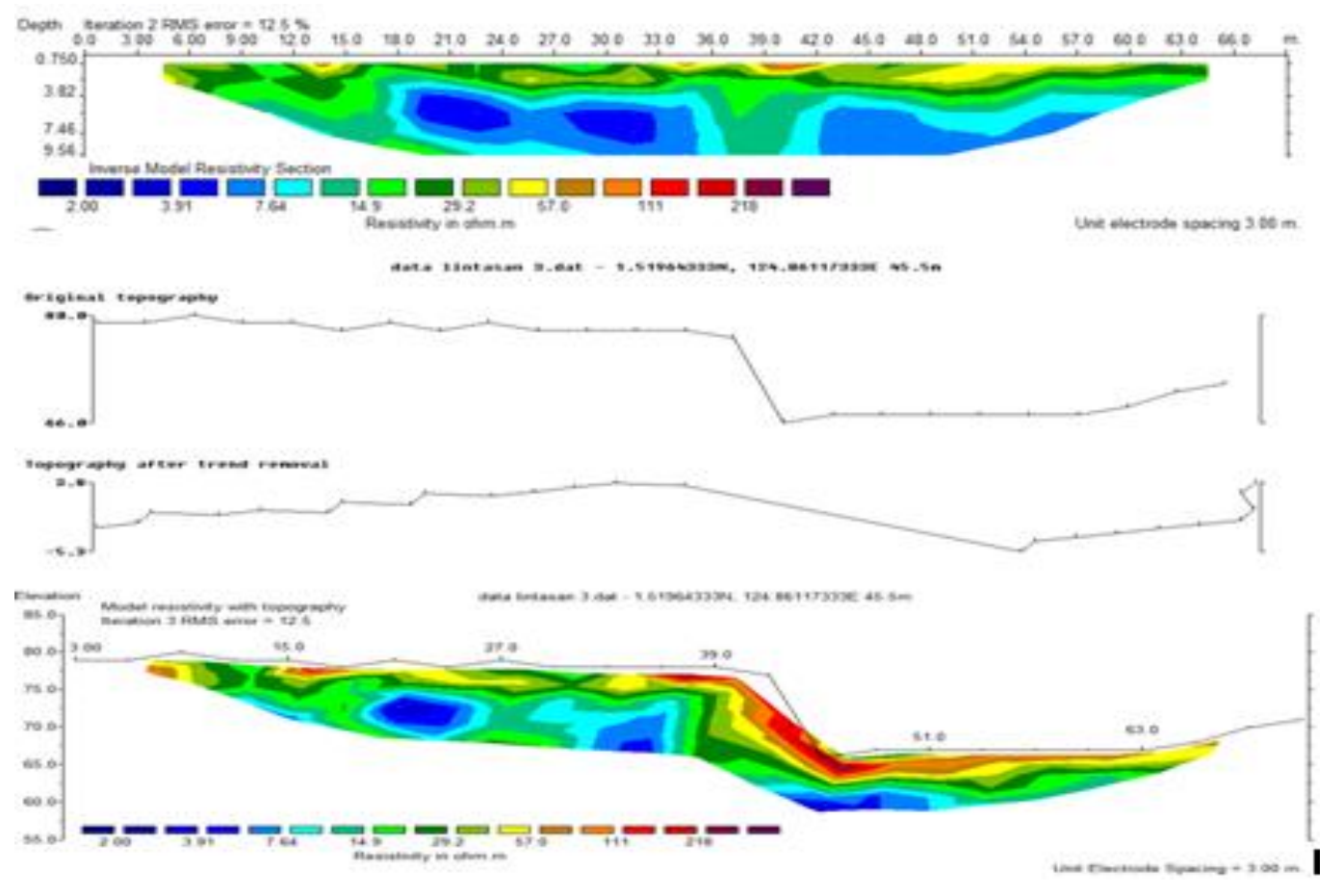

Gambar 5. Citra resistivitas pada lintasan 3 


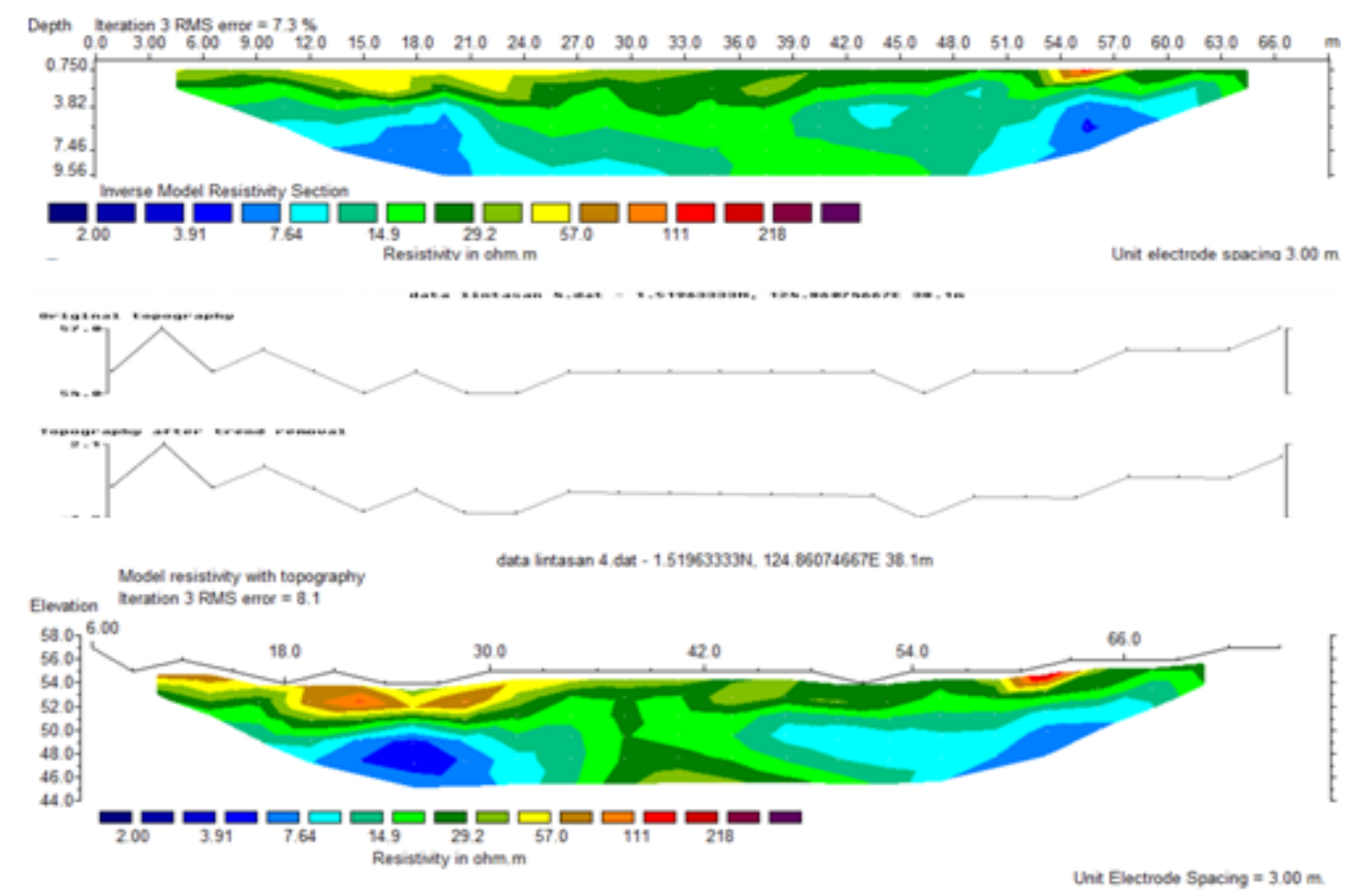

Gambar 6. Citra resistivitas pada lintasan 4

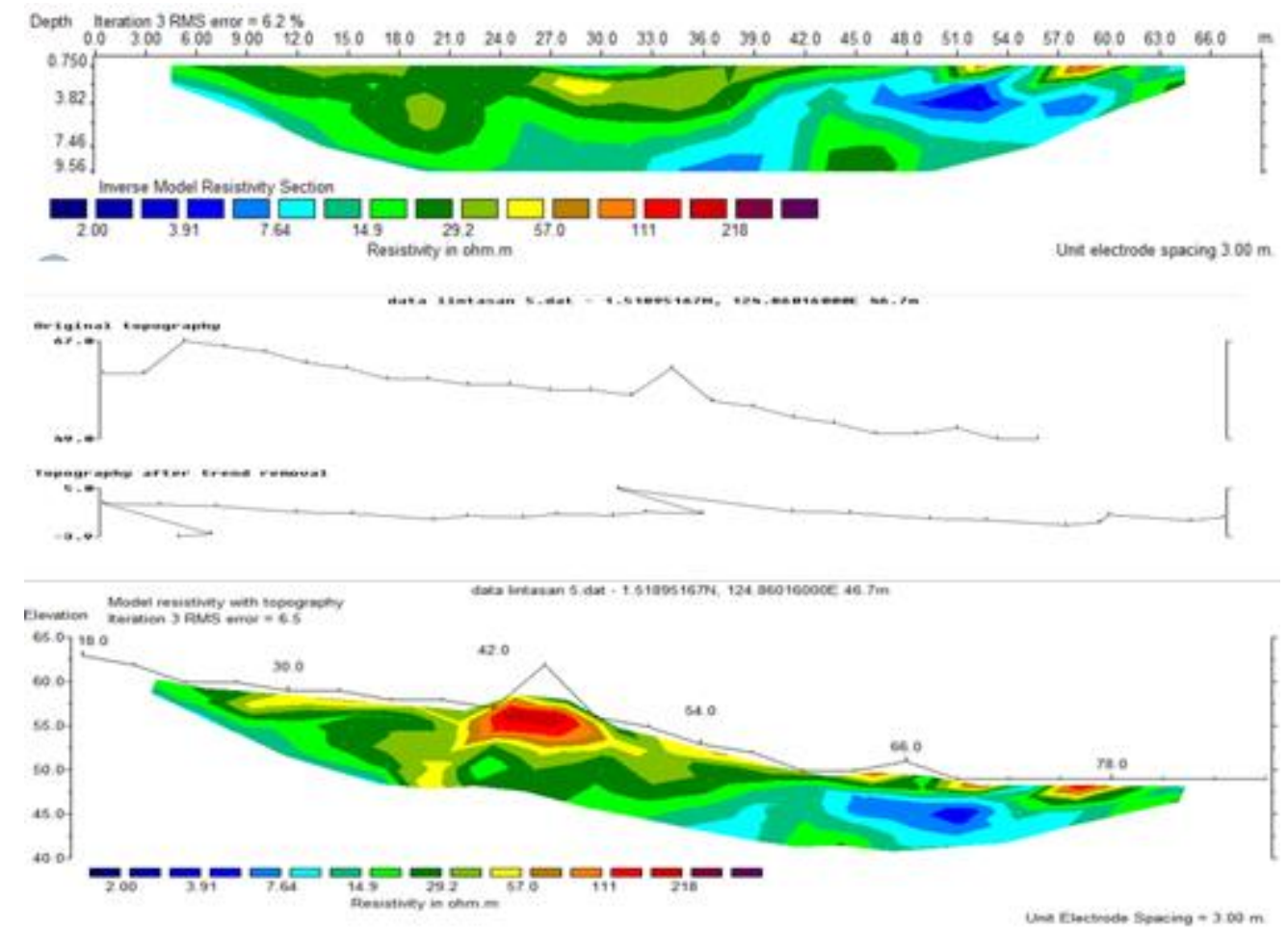

Gambar 7. Citra resistivitas pada lintasan 5.

Berdasarkan citra resistivitas terlihat adanya rembesan lindi yang kemudian terakumulasi di bawah permukaan pada Lintasan 1. Hal ini mengindikasikan bahwa daerah ini telah tercemar. Luas pencemarannya dapat diperkirakan dari citra yang dihasilkan. Potensi pencemaran air tanah permukaan kemudian semakin kecil seiring bertambahnya jarak dari TPA (lintasan 2 hingga lintasan 5). Relatif pendeknya lintasan 
yang digunakan $(72 \mathrm{~m})$, terkendala oleh topografi daerah kajian, berimbas pada kedalaman penampang vertikal pengukuran resistivitas yang hanya berkisar antara $10 \mathrm{~m}$ (untuk konfigurasi wenner-schlumberger) hingga $14 \mathrm{~m}$ (untuk konfigurasi dipoledipole). Kemungkinan ditemukannya pencemaran sebagai hasil rembesan dari kolam lindi dan lokasi penampungan sampah yang dapat mencemari air tanah dalam dapat diperoleh dengan menambah panjangnya lintasan pengukuran.

\section{KESIMPULAN}

$\begin{array}{ccc}\text { Investigasi } & \text { menggunakan } & \text { geolistrik } \\ \text { tahanan jenis } & \text { konfigurasi } & \text { Wenner- }\end{array}$ Schlumberger di TPA Sumompo, secara khusus pada daerah sekitar kolam lindi, menunjukkan adanya rembesan lindi yang terakumulasi dikedalaman $2-10 \mathrm{~m}$ terutama pada lintasan pengukuran 1 yang berjarak 50 $\mathrm{m}$ dari kolam lindi. Pada jarak $100-300 \mathrm{~m}$ dari kolam lindi juga ditemukan zona-zona bawah permukaan dengan nilai resistivitas rendah yang diinterpretasikan sebagai daerah jenuh air. Pola citra resistivitas bernilai rendah pada ke lima lintasan diperkirakan terkoneksi sehingga berimplikasi pada besarnya potensi tercemarnya tandon-tandon air permukaan oleh lindi.

\section{DAFTAR PUSTAKA}

Loke, M.H., Barker, R.D. 1996. Rapid leastsquares inversion of apparent resistivity pseudosections using a quasi-Newton method. Geophysical Prospecting 44, 131-152.

Ngadimin, Handayani, G. 2001. Aplikasi

Metode Geolistrik untuk Alat

Monitoring Rembesan Limbah

(Penelitian Model Fisik di

Laboratorium). JMS 6 (1), 43 - 53.

Oladapo, M.I, Adeoye-Oladapo, O.O., Adebobuyi, F.S. 2013. Geoelectric Study of Major Landfills in the Lagos Metropolitan Area, Southwestern Nigeria. International Journal of Water Resources and Environmental Engineering 5 (7), 387 - 398.

Suhendra. 2006. Pencitraan Konduktivitas Bawah Permukaan dan Aplikasinya untuk Identifikasi Penyebaran Limbah Cair dengan Menggunakan Metode Geolistrik Tahanan Jenis 2D. Jurnal Gradien 2 (1), 105 - 108.

Telford, W.M., Geldart, L.P., Sheriff, R.E. 1990. Applied Geophysics $2^{\text {nd }}$ Edition. Cambridge University Press, USA.

Wahyono, S.C., Sari, N. 2007. Penentuan Kontaminasi Limbah Cair dengan Metode Geolistrik. Jurnal Sains MIPA 13 (3), $183-189$.

Widyatmoko,H dan Sintorini, 2000, Menghindari, Menyingkirkan dan Mengolah Sampah. Jakarta: Abdi Tandur Program Studi Ilmu Lingkungan Universitas Udayana, Bogor 